\title{
DONOR SELECTION: GENERAL ASPECTS
}

\author{
${ }^{1}$ Simone Cunha Maradei Pereira, ${ }^{2}$ Aline Miranda de Souza, ${ }^{1}$ Luis Fernando Bouzas, ${ }^{1}$ Danielli Cristina Muniz de \\ Oliveira
}

1 INCA, 2 Grupo Gestor de Serviços de Hemoterapia (GGSH)

Hematopoietic stem cell transplantation (HSCT) provides potential curative treatment for a wide range of potentially fatal hematological diseases. The number of patients treated with HSCT has greatly increased in the past four decades, accompanied by steady improvement in results. Ideally, HSCT is performed with stem cells collected from an HLA compatible sibling, but this is not always possible, as only about $30 \%$ of patients will have this donor. The expansion in alternative sources of donor stem cells, together with the advent of reduced intensity conditioning regimes $(\mathrm{RIC})$, contributed to the increase in the number of HSCT in general and in transplantation with unrelated donors in particular. Advances in HLA typification have facilitated improved donor selection, which, in turn, has improved the outcome of HSCT with unrelated donors, so that survival is now approaching transplantation with related donor.

In addition, the improved safety of haploidentical transplantation with modern approaches, such as post-transplantation cyclophosphamide (PTCy), has led to an increase in the use of haploid donors.

The selection of a donor is a critical element that contributes to the success of HSCT. Considering HLA compatibility as the most important criterion in this choice, other factors can influence the outcome of the transplant, such as age and sex of the donor, parity in the case of female donors, $A B O$ compatibility and CMV serological status.

\section{AGE}

As older patients are eligible for HSCT, older siblings are increasingly being proposed as related donors. This data has been extensively studied because it is known that older donors are more likely to exhibit indeterminate potential clonal hematopoiesis (CHIP), and this has been associated with an increased risk of hematological malignancies $[1,2,3]$.

In 2015, Andrew $R$ et al demonstrated that there was no difference in transplant-related toxicity and concluded that graft from donors older than 60 years did not adversely affect the results of the allogeneic BMT when compared with graft from younger donors. No significant difference was observed in neutrophil and platelet recovery time, except for an average delay of 1.3 days in neutrophil recovery between patients undergoing myeloablative transplantation with older donors $(P=0.04)$. Myeloablative and non-myeloablative transplant recipients with older sibling donors had significantly lower grade II-IV GVHD than recipients with younger unrelated donor grafts. The rates of grade III-IV acute GVHD, chronic GVHD and TRM for recipients with older donors were not significantly different from recipients with younger donors. [4]

These data have been controversial in the literature. In a study by Kollman et al, donor age under 30 years was associated with a $30 \%$ incidence of acute GVHD compared to $34 \%$ in patients with donors over 30 years $(p=0.005)$. The improvement in survival was also observed in younger donors aged 18-30, 31-45 and 45 years old, being associated with an overall survival (OS) in 5 years of $33 \%, 29 \%$ and $25 \%$, respectively $(p=0,0002)$. [5]

In a 2015 study with HLA-compatible donors, sibling donors over 50 were associated with a 3 years OS of $54 \%$ compared to $72 \%$ in URDdonors under 50 ( $p<0.0001$ ). TRM and relapse occurred in $20 \%$ and $39 \%$ of transplants from donors over 50 years-old, compared with $8 \%$ and $28 \%$, respectively, after the younger donor transplant $(p=0.03)$. [6]

However, these data were not confirmed by Shaw B et al. analysing a cohort of URD transplantation. Donor age was not associated with recurrence and when tested as a continuous variable, it was also not associated with risk of relapse $(\mathrm{HR}, 1.004 ; 95 \% \mathrm{Cl}, 0.99-1.01$; $\mathrm{P}$ $=0.20$ ). The only donor characteristic associated with a lower risk of recurrence was the transplantation of female multiparous donors compared to male donors. [7] However, In the same study, donor younger age was associated with better survival, with 2 year-survival $3 \%$ better when a donor 10 years younger is selected. These results support previous studies that suggest prioritizing a younger $8 / 8 \mathrm{HLA}$ compatible donor. [7] 
The use of younger donors was also associated with higher doses of cells in the graft, better immunological reconstitution and easier collection. [8]

The donor's older age was also associated with an increase in acute GVHD, but not in chronic GVHD. The higher rates of grade 2 to 4 acute GVHD observed after transplantation of grafts from older donors can be explained by the replacement of naive T cells with memory $T$ cells as the immune system ages in older donors.[9]

In the context of Haplo-HSCT, the main criterion continues to be the absence of anti-HLA antibodies directed against the donor present in the recipient serum (DSA - Donor Specific Antibodies). In the case of positive DSA research and in the absence of an alternative donor, there are desensitization protocols. The other criteria are impossible to prioritize: age, sex, CMV and blood type. [10]

\section{SEX}

The impact of the difference between the sex of the donor and the sex of the recipient is still controversial. The selection of a male donor has been reported in some studies to be a factor with a positive impact on overall survival, regardless of the recipient's gender $[11,12]$ and many studies show worse prognosis when the donor is female and the recipient is male [13-20]; however, new studies have shown that there are many other factors that influence these outcomes such as female donor parity [5], the type of conditioning used [13) and the number of cells collected [21].

Several authors credit the higher incidence of chronic GVHD in transplants performed with female donors to male donors to the immune response against minor histocompatibility antigens present on the $\mathrm{Y}$ chromosome of male recipients ( $\mathrm{HY}$ antigens) [19,22-25], and other authors believe that this effect it is even more intense in the case of donors who have been pregnant with male fetuses or received transfusions from male donors and therefore have already been exposed to HY antigens [26-28]. Copelan et al, on the other hand, reported that the higher incidence of chronic GVHD in male patients who received cells from female donors was protective due to a lower incidence of relapse of the underlying disease [29]. Studies with a small number of individuals included suggest that, in the pediatric setting, the donor's gender has less influence on outcomes, especially if the donor is under the age of 12 , and therefore this criterion should be taken into account in the donor for the pediatric population $[30,31]$.
As for the type of conditioning proposed, a study that evaluated more than 1,000 adult patients demonstrated that among patients who received myeloablative conditioning regimen, male recipients of female donors had a higher incidence of chronic graft versus host disease $(p=0.01)$, higher mortality not related to recurrence $(p=0.022)$ and a lower overall survival $(p=0.018)$. Among patients who received reduced intensity conditioning, male recipients of female donors had a higher incidence of acute graft versus host disease $(p=0.01)$, but there was no statistical difference in terms of mortality rate, unrelated to recurrence. Among patients who received conditioning based on total lymphoid irradiation and anti-thymocytic globulin, there was no influence of donor's gender on the incidence of acute or chronic GVHD or mortality not related to recurrence; however, only in this group a statistically significant reduction in recurrence was noted $(p=$ 0.01 ) and the anti HY alloantibodies titers were predictors of protection against recurrence. Also in this group of patients, the gender difference between donor and recipient resulted in a longer overall survival $(p=0.037)$, probably related to a greater graft against leukemia effect [13].

Kollman led a study that included almost 7,000 transplants and found no effect of donor sex on overall survival, acute graft versus host disease (GVHD) or engraftment, however, when only bone marrow recipients were analyzed, female donors were associated to a greater risk of developing chronic graft versus host disease (GVHD), but this effect was restricted to donors with previous pregnancies $(p=$ 0.0001 ) and nulliparous donors had no statistical difference.The same analysis was not performed for peripheral blood source.[18]

Considering the use of umbilical cord blood, small studies suggest a higher incidence of chronic graft versus host disease when male recipients receive cord blood cells from a female donor $(p=0.02)$, while female recipients of male cord blood cells showed higher platelet engraftment failure $(p=0.02)$ [34], suggesting this scenario needs further studies.

An important aspect in the case of bone marrow collection is the size and weight of donors and in general, male donors offer a greater volume of bone marrow [21]. Data from the National Marrow Donor Program (NMDP) reveal that the average bone marrow volume donated by male donors is $1.1 \mathrm{~L}$, with $25 \%$ of men able to donate more than $1.35 \mathrm{~L}$. Female donors are able to donate, on average, 1L. [21] In addition, when the requested source is peripheral blood cells, men have a higher average CD34 + 
pre-apheresis cell count, which leads to differences of more than $30 \%$ in the total of CD34 + cells collected, even when adjusted by the donor weight besides the fact male donors more often have adequate peripheral venous access for collection by apheresis.[21]

\section{ABO INCOMPATIBILITY}

$A B O$ incompatibility is not a barrier to the success of hematopoietic progenitor cell transplantation because $A B O$ group antigens are not expressed in pluripotent cells or in the early stages of differentiation [33], even though, each type of incompatibility presents specific potential adverse events as well as preventive measures to be taken and all patients and their respective possible donors should be tested for ABO group, preferably before collection [34].

There are three types of $A B O$ incompatibility:

- Major: occurs when the recipient has isohemagglutinins directed against the donor's erythrocyte antigens. About 20 to $25 \%$ of transplants performed worldwide have this type of incompatibility. [35]

- Minor: occurs when the donor has isohemagglutinins against the recipient. About 20\% of transplants have this type of incompatibility. [35]

- Bidirectional: occurs when major and minor incompatibilities are present, as, for example, in the case of a donor $A$ to a recipient $B$. This type of incompatibility occurs in up to $5 \%$ of transplants.[35] A study conducted by Rowley et al showed that the infusion of 10 to $30 \mathrm{~mL}$ of incompatible red blood cells infused with cells from a donor with in a setting of major ABO incompatibility can be well tolerated by adults and when this volume is less than $15 \mathrm{~mL}$ there are no signs of clinical hemolysis [36] while Bolan et al showed that late hemolysis resulting from the infusion of progenitor cells from a donor with minor incompatibility can be severe and difficult to diagnose.[37]

The medium and long-term clinical impact of $A B O$ incompatibility is still controversial, while large studies have shown that greater or lesser incompatibility does not lead to significant impacts on overall survival and does not constitute a contraindication for donor selection [38], many smaller studies, mostly unicentric, show decreased overall survival rates, higher treatment-related mortality and even a higher incidence of graft-versus-host disease, in addition to greater and more prolonged red cell transfusion dependence. $[39,40]$
A study involving more than 5,000 unrelated allogeneic transplants performed in Japan for malignant and non-malignant diseases showed that in the period from 1993 to 2005, patients undergoing transplantation with an unrelated $A B O$ incompatible donor had worse overall survival and higher rates of treatment related mortality. Subsequently, the same group analyzed the transplants performed between 2000 and 2006 and again showed that the greater $A B O$ incompatibility was associated with worse overall survival $(p=0.004)$ and higher treatment-related mortality ( $p=0.001)$, however, when the same analyzes were carried out with transplants performed between 2007 and 2015, the greater incompatibility had no effect on overall survival $(p=$ 0.79). Thus, these authors concluded that the clinical significance of $A B O$ incompatibility has decreased over time. [38]

On the other hand, Watz et al studied 310 patients who underwent transplants with reduced intensity conditioning and showed that both patients with greater incompatibility and those with lesser incompatibility required red blood cell transfusions for a longer period than patients without incompatibility. [39]

Brazilian studies by Soares Júnior et al [41] in the southeastern region and by $\mathrm{Paz}$ et al [42] in the south, show similar results and do not show an impact on overall survival, the development of graftversus-host disease or transplant related mortality in patients who received cells from donors with $A B O$ incompatibility. The study conducted by De Santis et al [43] showed that in the case of greater $A B O$ incompatibility, patients who had antibody titers $\geq 32$ of IgG, but not IgM, needed a greater number of red blood cell transfusions than those who had lower titers.

\section{STATUS}

Cytomegalovirus (CMV) diseases are the main causes of significant morbidity and mortality in HSCT recipients. [44] The risk of CMV recurrence depends on the level of immunological competence, manifested as impaired T-cell immunity, including the presence and function of CMV-specific cytotoxic T lymphocytes [45].

Most events of $\mathrm{CMV}$ recurrence occur between 2 and 4 months, with a median of 44 days after HSCT [6264]. The greatest risk of $C M V$ reactivation and $C M V$ disease is reported for HIV-positive recipients regardless of the donor's serological status. [45] 
Other risk factors associated with a higher risk of recurrence are: transplantation with unrelated donor or HLA disparity [46-47-48], acute GVHD $[48,49,50,51]$, bone marrow as stem cell source [46], reduced intensity conditioning [49], conditioning based on TBI [48.51] and steroid use [51]. A protective effect of sirolimus use on GVHD prophylaxis was demonstrated in one study[46]. Sirolimus possibly has a protective effect against CMV infection due to the inhibition of cell signaling pathways that are triggered during CMV infection for the synthesis of viral proteinsThese antiproliferative properties probably inhibit CMV replication kinetics[52,53].

The importance of donor serological status is controversial. A large European registry study showed that seronegative patients who received grafts from unrelated seropositive donors had a decreased overall survival (HR 1.13 [1.06-1.21]; $p<0.01$ ) compared to seronegative donors, while no difference was observed in patients who received grafts from compatible siblings. In contrast, seropositive patients who received grafts from non-seropositive donors improved overall survival (HR 0.92 [0.86-0.98]; $p$ $<0.01)$ compared to seronegative donors, if they had received myeloablative conditioning this effect was absent in the context of reduced intensity conditioning. These data are not confirmed when the donor is related. Although no study has validated the role of CMV in haplo transplant, the available data suggest that there is an increase in the rate of CMV reactivation after haplo compared to related and unrelated donors BMT $[55,56]$ Therefore, reducing the risk of CMV can be particularly important for patients submitted to haplo transplant platforms.

\section{DONOR SAFETY DURING HSCT}

The hematopoietic stem cell donation is a voluntary and altruistic act, and the initial medical donor evaluation must consider aspects related to donor safety.

In general, the recommendations related to unrelated donors are more restrictive than the ones for related donors. In terms of age limit, for instance, NMDP unrelated donors are allowed to donate until 60 years-old while older related donors are accepted in USA and donors younger than 18 years-old are eligible exclusively for related donation. Considering the eventual risks, the American Pediatric Society published in 2010, a list of minimum criteria for children donation: 1) Absence of equivalent adult donor, in terms of compatibility; 2) A relevant relation between donor and receptor; 3) The clinical and emotional risks for donor are acceptable when compared to receptor benefits; 4) A formal authorization from parents or other legal representative is required.

Related and unrelated donors' medical evaluation should include a physical examination, a medical interview with emphasis on previous diseases, illegal drugs abuse, surgeries, blood transfusions, pregnancy and travels; and testing for infectious disease or other conditions that require additional data.

The laboratory tests performed during work up are: Complete blood count, biochemistry tests including liver function tests; Infectious disease markers for HIV, HTLV-1 and HTLV-II, hepatitis (HAV, HBV and HCV), Chagas disease, syphilis, CMV and EBV.

In the case of a positive test for an infectious disease marker like $B$ hepatitis the risks for receptor must be considered and the patient should be informed. However, an HIV positive test is a definitive exclusion criterium for related and unrelated donors. Pregnancy test is recommended for female donors younger than 55 years old. Hemoglobin electrophoresis can be requested for donors who report familial history of hemoglobinopathies but falcemic trait or minor talassemia do not represent risk for receptor. X-ray test and electrocardiogram can be requested for specific cases.

Related and unrelated donors should be oriented about the donation risks as well as eventual benefits for patient, and an informed consent form should be obtained during the work up process. The professionals responsible for donor evaluation should not be related to patient treatment for the purpose of reducing any conflict of interests.

In order to assure the donor safety during bone marrow harvest, donors with hemoglobin level lower than $13 \mathrm{~g} / \mathrm{dl}$ have the recommendation for collection of autologous blood and the prescription of iron supplements is also indicated as strategies to avoid symptomatic anaemia.

After bone marrow collection, serious complications are rare but donors can complaint of local pain and the use of analgesic drugs is also recommended. In the case of mobilized peripheral blood apheresis, donors can require analgesia to treat symptoms associated to filgrastim use. Complications associated to apheresis include the use of central venous catheter while splenic rupture is a rare but serious event.

Finally, some donors can be requested for a subsequent donation. The interval between the first and the second procedure should be evaluated on an 
individual basis but, as a general recommendation, donors submitted to apheresis as the first stem cell source should wait at least 30 days before a second donation while after a bone marrow donation the recommended interval is 90 days.

\section{CONSIDERATIONS FOR COVID-19}

The COVID-19 pandemic represented an additional challenge on the complex process related to hematopoietic stem cell donation.

According to the World Marrow Donor Association (WMDA), the main recommendations should balance additional donor risks, the benefits of (59)

- Clinical evaluation for related and unrelated donors should include epidemiological aspects and risk factors associated to COVID-19

- Swabbing all donors for SARS-CoV-2 prior to donation (e.g.at work-up or before G-CSF) has some potential value.

\section{REFERENCES}

1. Steensma DP, Bejar R, Jaiswal S, Lindsley RC, Sekeres MA, Hasserjian RP, Ebert BL. Clonal hematopoiesis of indeterminate potential and its distinction from myelodysplastic syndromes. Blood. v.126, n.1,p. 9-16. 2015.

2. Frick $M$, et al. Role of Donor Clonal Hematopoiesis in Allogeneic Hematopoietic Stem-Cell Transplantation. J Clin Oncol. 2019. PMID: 30403573 Clinical Trial.

3. Nawas MT, Schetelig J, Damm F, Levine RL, Perales MA, Giralt SA, VanDenBrink MR, Arcila ME, Zehir A, Papaemmanuil E, Klussmeier A, Schmidt $\mathrm{AH}$, Maiwald S, Bolton KL, Tamari R. The clinical implications of clonal hematopoiesis in hematopoietic cell transplantation. Blood Rev. p. 1007, 24 aug. 2020.

4. Rezvani AR, et al. Impact of donor age on outcome after allogeneic hematopoietic cell transplantation. Biol Blood Marrow Transplant. v.21, n.1, p. 105, 2015.

5. Kollman C, Eapen M. The effect of donor characteristics on survival after unrelated donor transplantion for hematologic malignancy. Blood. v.21, n.1, p. 105, 2015.
- Swabbing all donors for SARS-CoV-2 on the day of donation has no value, because it does not prevent harm to the donor or to the recipient, because there is no evidence for pre-symptomatic viraemia.

- In case of diagnosis of COVID-19, donor must be excluded from donation for at least 28 days after full recovery of symptoms but this time can be reviewed on specific cases.

- In case of close contact with a person diagnosed with SARS-CoV-2, the donor shall be excluded from donation for at least 28 days but this time can be reviewed.

- Quarantine of product is NOT recommended considering the lack of evidence of SARS-Cov-2 transmission.

The recommendations from Brazilian authorities are described on NOTA TÉCNICA № 36/2020-CGSNT/ DAET/SAES/MS (60) which establishes the RT-PCR testing $24 \mathrm{~h}$ prior the donation for all donors

6. Bastida JM, Cabrero M, Lopez-Godino O, Lopez-Parra M, Sanchez-Guijo F, Lopez-Corral L, et al. Influence of donor age in allogeneic stem cell transplant outcome in acute myeloid leukemia and myelodisplastic syndrome. Leukemia research. v.39, p. 828-834, 2015.

7. Shaw EB, Logan BR, Lee S.Development of an Unrelated Donor Selection Score Predictiveof Survival after HCT: Donor Age Matters Most. Biol Blood Marrow Transplant v.24, 2018,.

8. Paulin T, Ringden O, Nilsson B. Immunological recovery after bone marrow transplantation: role of age, graft-versus-host disease, prednisolone treatment and infections. Bone marrow transplantation. v.1, p. 317-328, 1987.

9. Miller RA.The aging immune system: primer and prospecties. Science. v.273, n.5271, p. 70-74, 1996.

10. Dubois V, Amokrane K, Nguyen S. Haploidentical hematopoietic stem cell transplant: How to choose the best donor?BGuidelines from the Francophone Society of Bone Marrow Transplantation and Cellular Therapy (SFGM-TC). Bull Cancer v. 107, n.15, p. 72-84, jan. 2020. 
11. Jernberg ÅG, Remberger M, Ringdén O, Winiarski J. Risk factors in pediatric stem cell transplantation for leukemia. Pediatr Transplant. 2004.

12.Pond GR, Lipton JH, Messner HA. Long-term survival after blood and marrow transplantation: Comparison with an age- and gender-matched normative population. Biol Blood Marrow Transplant. 2006.

13. Nakasone $\mathrm{H}$, Remberger M, Tian L, Brodin P, Sahaf $B$, Wu F, et al. Risks and benefits of sex-mismatched hematopoietic cell transplantation differ according to conditioning strategy. Haematologica. 2015.

14. Gratwohl A, Stern M, Brand R, Apperley J, Baldomero H, De Witte T, et al. Risk score for outcome after allogeneic hematopoietic stem cell transplantation: A retrospective analysis. Cancer. 2009.

15. Jagasia M, Arora M, Flowers MED, Chao NJ, McCarthy PL, Cutler CS, et al. Risk factors for acute GVHD and survival after hematopoietic cell transplantation. Blood. 2012.

16. Flowers MED, Inamoto Y, Carpenter PA, Lee SJ, Kiem HP, Petersdorf EW, et al. Comparative analysis of risk factors for acute graft-versus-host disease and for chronic graft-versus-host disease according to National Institutes of Health consensus criteria. Blood. v.117, n.11, p. 3214-3219, 2011.

17. Kanda J, Nakasone H, Atsuta Y, Toubai T, Yokoyama $\mathrm{H}$, Fukuda T, et al. Risk factors and organ involvement of chronic GVHD in Japan. Bone Marrow Transplant. 2014.

18. Kollman C. Donor characteristics as risk factors in recipients after transplantation of bone marrow from unrelated donors: the effect of donor age. Blood. v.98, p.2043-2051, 2001.

19. Popli R, Sahaf B, Nakasone H, Lee JYY, Miklos DB. Clinical impact of H-Y alloimmunity. Immunologic Research. 2014.

20. Nannya Y, Kataoka K, Hangaishi A, Imai Y, Takahashi T, Kurokawa $M$. The negative impact of female donor/male recipient combination in allogeneic hematopoietic stem cell transplantation depends on disease risk. Transpl Int. 2011.

21. Confer DL, Miller JP. Optimal Donor Selection: Beyond HLA. Biol Blood Marrow Transplant. 2007.
22. Miklos DB, Kim HT, Miller KH, Guo L, Zorn E, Lee $\mathrm{SJ}$, et al. Antibody responses to $\mathrm{H}-\mathrm{Y}$ minor histocompatibility antigens correlate with chronic graft-versus-host disease and disease remission. Blood. 2005.

23. Sahaf $B$, Yang $Y$, Arai S, Herzenberg LA, Herzenberg LA, Miklos DB. H-Y antigen-binding $B$ cells develop in male recipients of female hematopoietic cells and associate with chronic graft vs. host disease. Proc Natl Acad Sci U S A. 2013.

24. Nakasone H, Tian L, Sahaf B, Kawase T, Schoenrock K, Perloff S, et al. Allogeneic HY-antibodies detected 3 months after female-to-male HCT predict chronic GVHD and nonrelapse mortality in humans. Blood. 2015.

25. Miklos DB, Kim HT, Zorn E, Hochberg EP, Guo L, Mattes-Ritz A, et al. Antibody response to DBY minor histocompatibility antigen is induced after allogeneic stem cell transplantation and in healthy female donors. Blood. 2004.

26. Flowers MED, Pepe MS, Longton G, Doney KC, Monroe D, Witherspoon RP, et al. Previous donor pregnancy as a risk factor for acute graft-versushost disease in patients with aplastic anaemia treated by allogeneic marrow transplantation. Br J Haematol.1990.

27. Carlens $S$, Ringdén $O$, Remberger $M$, Lönnqvist $B$, Hägglund $\mathrm{H}$, Klaesson $\mathrm{S}$, et al. Risk factors for chronic graft-versus-host disease after bone marrow transplantation: A retrospective single centre analysis. Bone Marrow Transplant. 1998.

28. Vogt MHJ, Van den Muijsenberg JW, Goulmy E, Spierings E, Kluck P, Kester MG, et al. The DBY gene codes for an HLA-DQ5-restricted human male-specific minor histocompatibility antigen involved in graft-versus-host disease. Blood. 2002.

29. Copelan EA. Medical Progress: Hematopoietic Stem-Cell Transplantation. New Engl J Med. 2006.

30. Kutnik P, Kwiatkowska A, Krawczyk D, Polak O, Jawoszek P, Puchała $D$, et al. The impact of donor-recipient sex matching on transplantrelated complications in children after allogeneic haematopoietic stem cell transplantation - A single-centre, retrospective study. Pediatr Pol. 2019.

31. Friedrich $P$, Guerra-García P, Stetson A, Duncan C, Lehmann L. Young Female Donors Do Not Increase the Risk of Graft-versus-Host Disease or Impact Overall Outcomes in Pediatric HLA- 
Matched Sibling Hematopoietic Stem Cell Transplantation. Biol Blood Marrow Transplant. 2018.

32. Konuma T, Kato S, Ooi J, Oiwa-Monna M, Ebihara Y, Mochizuki S, et al. Impact of sex incompatibility on the outcome of single-unit cord blood transplantation for adult patients with hematological malignancies. Bone Marrow Transplant. 2014.

33. Sieff C, Bicknell D, Caine G, Robinson J, Lam G, Greaves MF. Changes in cell surface antigen expression during hemopoietic differentiation. Blood. 1982.

34.Daniel-Johnson J, Schwartz J. How do i approach $\mathrm{ABO}$-incompatible hematopoietic progenitor cell transplantation? Transfusion. 2011.

35. Worel N, Kalhs P. AB0-incompatible allogeneic hematopoietic stem cell transplantation. Haematologica. 2008.

36. Rowley SD, Liang PS, Ulz L. Transplantation of $\mathrm{ABO}$-incompatible bone marrow and peripheral blood stem cell components. Bone Marrow Transplant. 2000.

37. Bolan CD, Childs RW, Procter JL, Barrett AJ, Leitman SF. Massive immune haemolysis after allogeneic peripheral blood stem cell transplantation with minor $A B O$ incompatibility. $\mathrm{Br} J \mathrm{Hae}-$ matol. 2001.

38. Kimura F, Kanda J, Ishiyama K, Yabe T, Yoshifuji $\mathrm{K}$, Fukuda T, et al. ABO blood type incompatibility lost the unfavorable impact on outcome in unrelated bone marrow transplantation. Bone Marrow Transplant. 2019.

39. Watz E, Remberger $M$, Ringden $O$, Lundahl J, Ljungman P, Mattsson J, et al. Analysis of donor and recipient $A B O$ incompatibility and antibody-associated complications after allogeneic stem cell transplantation with reduced-intensity

40. conditioning. Biol Blood Marrow Transplant. 2014.

41. Wang Y, Wu DP, Liu QF, Xu LP, Liu KY, Zhang XH, et al. Donor and recipient age, gender and $A B O$ incompatibility regardless of donor source: Validated criteria for donor selection for haematopoietic transplants. Leukemia. 2018.

42. Soares Júnior JA, Martinho GH, Macedo AV de, Verçosa MR, Nobre V, Teixeira GM. Assessing the impact of $A B O$ incompatibility on major allogeneic hematopoietic stem cell transplant outcomes: a prospective, single-center,
43. cohort study. Hematol Transfus Cell Ther. 2019.

44. Paz A, Rigoni L, Fischer G, Schittler M, Pezzi A, Valim V, et al. Donor characteristics and hematopoietic stem cell transplantation outcome: experience of a single center in Southern Brazil. Hematol Transfus Cell Ther. 2018.

45. De Santis GC, Garcia-Silva AC, Dotoli GM, de Castro, Pamela T Simões BP, Covas DT. Higher Anti-A/B isoagglutinin titers of IgG class, but not of $\lg M$, are associated with increased red blood cell transfusion requirements in bone marrow transplantation with major ABO-mismatch. Clin Transplant. 2017.

46. Meyers JD, Flournoy N, Thomas ED. Nonbacterial pneumonia after allogeneic marrow transplantation: a review of ten years experience. Rev Infect Dis. v.4, n.6,p.1119-1132, 1982.

47. Styczynski,J. Who is the patient at risk of CMV recurrence: A review of the current scientific evidence with a focus on hematopoietic cell transplantation. Infect Dis Ther. v.7, p. 1-16, 2018.

48. Marty FM,Bryar J, Browne SK. Sirolimus-based graft-versus-host disease prophylaxis protects against cytomegalovirus reactivation after allogeneic hematopoietic stem cell transplantation: a cohort analysis. Blood. v. 110, n.2, p.490-500, 2007.

49. Ozdemir E, Saliba RM, Champlin RE,. Risk factors associated with late cytomegalovirus reactivation after allogeneic stem cell transplantation for hematological malignancies. Bone Marrow Transpl. v. 40, n.2, p125-136, $2007 .$.

50. Kaito S, Nakajima Y, Hara K. Heterogeneous impact of cytomegalovirus reactivation on nonrelapse mortality in hematopoietic stem cell transplantation. Blood Advances v.4,n.6,p. 1051-1061, 2020.

51.Nakamae H, Kirby KA, Sandmaier BM. Effect of conditioning regimen intensity on CMV infection in allogeneic hematopoietic cell transplantation. Biol Blood Marrow Transpl. v.15, n.6, p. 694-703, 2009.

52. Takenaka K, Nishida T, Asano-Mori Y. Cytomegalovirus reactivation after allogeneic hematopoietic stem cell transplantation is associated with a reduced risk of relapse in patients with acute myeloid leukemia who survived to day 100 after transplantation:the Japan Society for Hematopoietic Cell Transplantation Transplantation-re- 
lated complication Working Group.Biol Blood Marrow Transpl. v.21, n.11, p.2002-2016, 2015.

53. Nichols WG, Corey L, Gooley T.Rising pp65 antigenemia during preemptive anticytomegalovirus therapy after allogeneic hematopoietic stem cell transplantation: risk factors correlation with DNA load, and outcomes. Blood. ,v, 97, n.4, p. 867-874, 2001.

54. Reddehase MJ, Balthesen M, Rapp M, Koszinowski, NH. The conditions of primary infection define the load of latent viral genome in organs and the risk of recurrent cytomegalovirus disease. J Exp Med. v.179, n.1, p. 185-193, jan.,1994.

55.Sagar B. Kudchodkar, Yongjun Yu, Tobi G. Maguire, James $C$. Alwine. Human cytomegalovirus infection alters the substrate specificities and rapamycin sensitivities of raptor- and rictor-containing complexes. Proc Natl Acad Sci U S A. v. 103, n. 38, p. 14182-14187, 19 jan., 2006.

56. J. Styczynski, K. Czyzewski, M. Wysocki, O. Gryniewicz-Kwiatkowska, A. Kolodziejczyk-Gietka, M. Salamonowicz, L. Hutnik, O. et al. Increased risk of infections and infection-related mortality in children undergoing haematopoietic stem cell transplantation compared to conventional anticancer therapy: a multicentre nationwide study.Clin microbiol Infect v.22, n.2, p.179, 2016.

57. Di Stasi A, Milton DR, Poon LM, Hamdi A, Rondon $\mathrm{G}$, Chen J, et al. Similar transplantation outcomes for acute myeloid leukemia and myelodysplastic syndrome patients with haploidentical versus 10/10 human leukocyte antigen-matched unre- lated and related donors. Biology of blood and marrow transplantation: journal of the American Society for Blood and Marrow Transplantation. v.20, p. 1975-1981, 2014.

58. Raiola A, Dominietto A, Varaldo R, Ghiso A, Galaverna F, Bramanti $S$, et al. Unmanipulated haploidentical BMT following non-myeloablative conditioning and post-transplantation $\mathrm{CY}$ for advanced Hodgkin's lymphoma. Bone marrow transplantation. v.49, p. 190-194, 2014.

59. Grupp SA, Frangoul $H$, Wall D, Pulsipher MA, Levine JE, Schultz KR. Use of G-CSF in matched sibling donor pediatric allogeneic transplantation: a consensus statement from the Children's Oncology Group (COG) Transplant Discipline Committee and Pediatric Blood and Marrow Transplant Consortium (PBMTC) Executive Committee. Pediatr Blood Cancer. v.46, n.4, p. 414421, apr., 2006.

60. Chan KW, Gajewski JL, Supkis D Jr, Pentz R, Champlin R, Bleyer WA. Use of minors as bone marrow donors: current attitude and management. A survey of 56 pediatric transplantation centers. J Pediatr. v.128, v.5-part 1, p. 644-648, may 1996.

61. Sahu KK, Siddiqui AD, Cerny J. COVID-19 pandemic and impact on hematopoietic stem cell transplantation. Bone Marrow Transplant. v.4, p.1-3, may 2020.

62. Testagem laboratorial conforme legislação vigente em RDC No 214, de 7 de fevereiro de 2018 n.214, p. 38-42, 7 fev.,2018. 